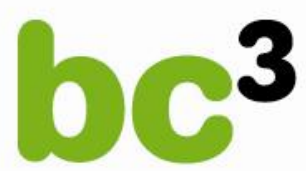

BASQUE CENTRE

FOR CLIMATE CHANGE

Klima Aldaketa Ikergai

\title{
The Long Run Demand for Lighting: \\ Elasticities and Rebound Effects in Different \\ Phases of Economic Development
}

Roger Fouquet and Peter J.G. Pearson

July 2011

BC3 WORKING PAPER SERIES

2011-06 
The Basque Centre for Climate Change (BC3) is a Research Centre based in the Basque Country, which aims at contributing to long-term research on the causes and consequences of Climate Change in order to foster the creation of knowledge in this multidisciplinary science.

The BC3 promotes a highly-qualified team of researchers with the primary objective of achieving excellence in research, training and dissemination. The Scientific Plan of BC3 is led by the Scientific Director, Prof. Anil Markandya.

The core research avenues are:

- Adaptation to and the impacts of climate change

- Measures to mitigate the amount of climate change experienced

- International Dimensions of Climate Policy

- Developing and supporting research that informs climate policy in the Basque Country

See www.bc3research.org for further details.

The BC3 Working Paper Series is available on the internet at http://www.bc3research.org/lits_publications.html

Enquiries (Regarding the BC3 Working Paper Series):

Roger Fouquet

Email: roger.fouquet@bc3research.org

www.bc3research.org

The opinions expressed in this working paper do not necessarily reflect the position of Basque Centre for Climate Change (BC3) as a whole.

Note: If printed, please remember to print on both sides. Also, perhaps try two pages on one side. 


\title{
The Long Run Demand for Lighting: Elasticities and Rebound Effects in Different Phases of Economic Development ${ }^{12}$
}

\author{
Roger Fouquet ${ }^{3}$ and Peter J.G. Pearson ${ }^{4}$
}

The provision of artificial light was revolutionised by a series of discontinuous innovations in lighting appliances, fuels, infrastructures and institutions during the nineteenth and twentieth centuries. In Britain, the real price of lighting fell dramatically (3,000-fold between 1800 and 2000) and quality rose. Along with rises in real income and population, these developments meant that total consumption of lighting was 40,000 times greater by 2000 than in 1800 . The paper presents estimates of the income and price elasticities of demand for lighting services over the past three hundred years, and explores how they evolved. Income and price elasticities increased dramatically (to 3.5 and -1.7, respectively) between the 1840 s and the 1890s and fell rapidly in the twentieth century. Even in the twentieth century and at the beginning of the twenty-first century, rebound effects in the lighting market still appear to be potentially important. This paper provides a first case study of the long run effects of socio-economic change and technological innovation on the consumption of energy services in the UK. We suggest that understanding the evolution of the demand for energy services and the factors that influence it contributes to a better understanding of future energy uses and associated greenhouse gas emissions.

Keywords: Energy Services, Demand, Economic Development, Rebound Effect.

JEL Classification: Q21, Q32, Q41, Q55

Cite as: Fouquet, R. and P.J.G. Pearson (2011) The Long Run Demand for Lighting: Elasticities and Rebound Effects in Different Phases of Economic Development. BC3 Working Paper Series 2011-06. Basque Centre for Climate Change (BC3). Bilbao, Spain.

\footnotetext{
${ }^{1}$ This paper has been commissioned for the inaugural issue of Economics of Energy and Environmental Policy 1(1) in January 2012. http://www.iaee.org/en/publications/eeepnextissue.aspx.

${ }^{2}$ We would like to thank Bill Nordhaus, David Stern, Lester Hunt and Lutz Killian for comments on the analysis of the paper. Of course, the authors of this paper are solely responsible for any errors.

${ }^{3}$ Basque Centre for Climate Change (BC3). Alameda Urquijo, 4 - 4॰ 48008 Bilbao, Spain; and IKERBASQUE, Basque Foundation for Science. Alameda Urquijo 36-5, 48011 Bilbao, Spain. Corresponding author E-mail: roger.fouquet@bc3research.org.

${ }^{4}$ Low Carbon Research Institute (LCRI), Cardiff University, United Kingdom.
} 


\section{Introduction}

From September 2012, the sale of incandescent light bulbs will be banned in the European Union. In the USA, the phase-out is targeted for 2014. Afterwards, subject to a few exceptions, only relatively energy efficient light bulbs, such as compact fluorescent lamps (CFLs), halogen bulbs and solid-state light emitting diodes (LEDs), will be sold. The switch to radically more efficient lighting sources is likely to have major and possibly complex implications for energy consumption associated with lighting, both in the short and long term.

Frondel and Lohmann (2011) estimated the potential electricity saving from the EU legislation to be $40 \mathrm{TWh}$ per year. Since 3,600 TWh of electricity were generated in the EU in 2010 (BP 2011), this would amount to a saving of about $1.1 \%$. However, not least because it reduces the cost of lighting services, an improvement in energy efficiency does not necessarily yield an equivalent reduction in energy consumption,. For instance, consumers with access to more efficient bulbs might increase their use or simply have less incentive to turn them off (Greening et al. 2000, Frondel et al. 2008), leading to potential rebound effects that limit policy effectiveness. ${ }^{5}$

The introduction of a new generation of improvements in energy efficient lighting is significant not just for the EU and the USA, but also for consumers across the world. While a ban on incandescent bulbs in some countries may not immediately engender a ban in others and could even lead to the dumping of incandescent bulbs in developing economies, in the longer run, the new wave of efficiency improvements means cheaper lighting across the world. In developing economies, in particular, the impact of efficiency improvements on energy consumption is unclear. Some have proposed that the rebound effects in developing economies have the potential to be far greater than in industrialised economies (Schipper 2000, Roy 2000).

On the basis of 'simple extrapolations of past behaviour into the future' and projections in which more efficient, cheaper solid state lighting (SSL) dominates, Tsao et al. (2010) reach two conclusions. First, 'there is a massive potential for growth in the consumption of light' (i.e., a ten-fold increase by 2030). Second, drawing on a 'simple energy economics framework' (a Cobb-Douglas production function and profit maximisation), this consumption growth has the potential to increase both human productivity and the associated energy consumption (i.e., doubling by 2030). The authors say that 'Whether history can be used in this case to predict the future cannot be known', and discuss reasons why such projected growth in the demand for light might or might not be moderated. The Economist (28 August 2010), drew on this paper with the headline 'Making lighting more efficient could

\footnotetext{
5 'Rebound' occurs where potential energy savings from greater energy efficiency are reduced (e.g. 20\% rebound means only $80 \%$ of expected savings actually occur). 'Backfire' occurs if energy consumption rises with efficiency. Rebound effects can be direct (e.g. substitution and income/output effects) and indirect (embodied energy and secondary effects), and there can be economy-wide macroenomic effects. For a review and classification, see Sorrell (2007) and Sorrell and Dimitropoulos (2007).
} 
increase energy use, not decrease it', and ended with the notion that the most effective way to reduce energy used for lighting might be to make incandescent bulbs compulsory rather than ban them.

There have been relatively few estimates of the long run demand for and elesticities of energy services, especially for lighting. Drawing significantly on the data from Fouquet and Pearson (2006), augmented from other sources and spanning three centuries, six continents and five lighting technologies, Tsao and Waide (2010) propose that the price and income elasticity of demand for lighting are close to unity - that is, a $10 \%$ percent increase in income or decrease in the price of lighting would raise lighting consumption by $10 \%$. They derived their elasticity estimates from a simple linear association between per capita light consumption and the ratio of per capita GDP to the cost of light. They state that while they think the expression plausible, they 'make no serious attempt to explain its origin.' While respecting the care with which they discuss this expression, we suggest that constant unitary elasticities over different phases and circumstances of economic development seem unlikely.

There appear to be few studies that examine how elasticities of energy service demand change through time or with income. Fouquet (2008 p.265) proposed that the nineteenth century in the United Kingdom was a period of very high income and price elasticities, especially for lighting and passenger transportation. However, no econometric analysis was performed to test these propositions. Thus, this paper seeks to estimate the income and real price elasticities of demand for lighting (rather than the full array of issues related to the rebound effect), and explore their evolution. This evidence could help towards a new perspective of the study of energy consumption at different phases of economic development.

Section 2 briefly reviews the literature on the demand for energy services. Section 3 outlines, the data sources for this study. Then, Section 4 presents and discusses the trends in lighting prices and consumption. In Section 5, the estimated trends in the price and income elasticities of demand for lighting are presented. The final section draws tentative conclusions about the variations in elasticities over time and at different phase of economic development and examines their implications for our understanding of long run energy consumption and climate policy.

\section{Demand for Energy Services}

Energy consumption is driven by the demand for the services energy can provide, such as space and water heating or cooling, powering of appliances, illumination and transportation (Goldemberg et al. 1985). To provide these services, it is necessary to combine energy with the appropriate technologies. 
When the efficiency of the technology improves, the (usually implicit) price/cost of the service falls, without any change in the price of the energy required (Howarth 1997, Haas et al. 2008).

Even if, over a few years, the efficiency improvements and, thus, the differences between the trends in the prices of energy and energy services are small, over several decades or a century, the accumulated divergences can be very large. Nordhaus (1996), for example, identified a major divergence between the trends in the price of lighting and the price of the fuels used for lighting in the nineteenth and twentieth centuries. Fouquet (2011) showed that, at least in the UK, these divergences between the costs of energy inputs and the cost of energy service outputs are common to all energy services. Such divergences have major implications for the signals and incentives driving energy consumption, and, therefore, are of importance to the study of long run trends in energy markets and climate change. Yet, mostly because of the lack of data, economists still tend to use commodity price series rather than those for energy services. This may be partly because of a lack of appreciation of the implications of not using them.

Two "straw-man" examples will be used to show that when we ignore service demand, we are actually making an implicit assumption about the price elasticity of demand for energy services. The 'efficiency optimist' might suggest that if energy efficiency improves by $10 \%$, energy consumption will fall by $10 \%$. The 'lazy economist' might propose that since the price of energy is unchanged consumption of energy will remain unchanged. Both stances ignore the impact on the cost of energy services and the associated income and substitution effects. However, since the efficiency has improved by $10 \%$, the consumer can get the same quantity of the service with $10 \%$ less energy. This implies that the price of the energy service has fallen $10 \%$. For energy consumption to fall by $10 \%$, energy service use must remain unchanged. So, the 'efficiency optimist' implicitly assumes that the price elasticity of demand for energy services is zero.

Similarly, in the case of the 'lazy economist', since the price of this energy service has fallen by $10 \%$., for energy consumption to remain unchanged, energy service use must increase by $10 \%$. So, the implicit assumption here is that the price elasticity of demand for energy services is one. Thus, focussing on energy rather than energy services will lead to misleading estimates of consumer responses to long run income, price and efficiency changes.

We suggest, therefore, that valuable insights might come from understanding the two-stage relationships, first, between energy service demands, income and energy service prices and, second, between delivered energy services, energy efficiencies and energy consumption. Inclusion of energy services in models should deepen our understanding of energy markets both in industrialised and developing economies (Modi 2004). This may be especially true in the twenty-first century, when great efforts are being made to develop new, more efficient and low carbon energy technologies. 
The literature on the rebound effect argues (often implicitly) that the price elasticity of demand for energy service cannot be assumed to be zero or one (Khazzoom 1980, Brookes 1990, Saunders 1992, Howarth 1997, Greening et al. 2000, Sorrell and Dimitropoulos 2007, Wei 2010). Nevertheless, the actual size of the price - and income - elasticities is an empirical matter. Given the importance of understanding long run energy behaviour, economists have recently begun to study and (however crudely) estimate the price and income elasticities of demand for energy services.

Jevons (1865) introduced the concept of the rebound effect, asserting the likelihood of 'backfire' in relation to coal: "....it is wholly a confusion of ideas to suppose that the economical use of fuel is equivalent to a diminished consumption. The very contrary is the truth.... Every improvement of the engine when effected will only accelerate anew the consumption of coal..." More recently, empirical studies have tended to estimate smaller rebound effects, indicating that in the cases investigated energy consumption would decline, all other things being constant, as a result of energy efficiency improvements (see Sorrell (2007) for a review of available estimates).

Ayres et al. (2005) propose that rebound effects related to 'macro' innovations (i.e. radical innovations, like the steam engine) can lead to large rebound effects and increases in energy consumption; whereas the 'micro' innovations that improve the efficiency of existing technologies tend to lead to smaller rebound effects. Fouquet (2008) presents a few historical cases in the UK where the rebound effect from efficiency improvements may have been greater than the energy saving - supporting Jevons' (1865) conjectures.

Looking specifically at lighting demand, Greening et al. (2000) propose the rebound effect in household illumination to be 5-12\%. Howarth et al. (2000) argue that, for business lighting, energy efficiency improvements reduce expenditure only by a small amount and, therefore, are unlikely to influence consumption behaviour. Schipper (2000) proposes that rebound effects vary, and may well be larger in developing economies than in industrialised countries or amongst poorer households in industrialised countries. Roy (2000) estimates that in poor rural households the rebound effect for lighting is very large - between $50 \%$ and $200 \%$. And, as we have seen, Tsao and Waide (2010) suggest that backfire will occur as a result of improvements in the efficiency of solid state lighting, in the face of unitary price and income elasticities. In the case of lighting services, there are very few studies that offer estimates of price elasticities and very few that identify income elasticities. Given the dearth of studies, this paper tries to contribute to this literature by estimating how the income and price elasticities of lighting demand have changed through time and at different phases of economic development in the UK. 


\section{Data Sources and Creation}

The identification of trends in the evolution of the cost and consumption of lighting requires statistical information on the prices of energy sources and lighting technology efficiencies. Here, we summarise the sources and methods - more detail may be found in Fouquet and Pearson (2006) and Fouquet (2008).

Information about the price of tallow candles (i.e., made from moulded animal fat) can be found from the fourteenth century to the eighteenth century for market towns across England (Rogers 1865-86) and between the sixteenth and nineteenth centuries, drawing on records from old English institutions, including Eton and Westminster Colleges, several Oxford and Cambridge colleges, Greenwich Hospital and the Navy (Beveridge 1926).

From 1823, town gas prices are available from various gas companies, mostly in the South-East of England, recovered from the British Parliamentary Papers (BPP) and, then from the successive ministries (MoFP 1951, MoP 1961, and DTI 1991, 1997 and 2001) associated with energy. From 1857, an average refined petroleum price series can be found in the BPP; from 1903, explicit prices for kerosene (also referred to as 'paraffin', 'lamp oil' or 'burning oil') are presented. Electricity prices are available from 1898 (Administrative Council of London 1920, MoFP 1951, MoP 1961, and DTI 1991, 1997 and 2001).

Using consumer price index data in Allen (2007), the costs of using different energy source and producing lighting are made broadly comparable across time, with prices expressed in real terms for the year 2000. Also, income and population data were used to analyse the factors driving consumption, (ONS 2010, Mitchell 1988, Broadberry et al. 2009).

Estimates of tallow candle consumption are available between 1711 and 1830, providing a useful early indicator of light consumption (Mitchell 1988 p. 412). Estimates of gas consumption for London are available from 1822; they have been extrapolated to indicate national consumption. British national consumption data start in 1881 (Mitchell 1988 p.269, BPP, then MoFP (1951), MoP (1961) and DTI (1991, 1997 and 2001). Statistics on petroleum consumption start from 1842 (BPP 1896). Kerosene consumption data are based initially on estimating the proportion of refined petroleum used as a lighting fuel and then, from 1910, actual kerosene data are provided in the statistical digests of the energy ministries. MoFP (1951) provides data on actual electricity used for lighting between 1924 and 1949. Mills (2002) indicates that in 199714 percent of United Kingdom electricity use was for lighting. For other years, interpolations of the share of electricity used for lighting are made - from Mitchell (1988 p. 263) and other standard energy digest sources. Table 1 shows the estimates of the proportions of each fuel that were used for lighting purposes for ten-year intervals from 1800 to 2000 . 
Table 1. Estimates of the Proportion of Fuel Consumption Used for Lighting (percentage shares), 1800-2000

\begin{tabular}{cccccccc}
\hline Year & Gas & Petroleum & Electricity & Year & Gas & Petroleum & Electricity \\
\hline 1800 & 100 & & & 1900 & 91 & 68 & 60 \\
1810 & 100 & & & 1910 & 89 & $60^{*}$ & 40 \\
1820 & 100 & & & 1920 & 80 & $22^{*}$ & 27 \\
1830 & 99 & & 1930 & 50 & 1 & $32^{*}$ \\
1840 & 98 & & & 1940 & 30 & & $37^{*}$ \\
1850 & 97 & 90 & & 1950 & 5 & & $45^{*}$ \\
1860 & 96 & 88 & & 1960 & 1 & & 38 \\
1870 & 95 & 85 & 98 & 1970 & & & 28 \\
1880 & 94 & 80 & 91 & 1980 & & & 26 \\
1890 & 93 & 75 & 85 & 1990 & & & $14^{*}$ \\
& & & & 2000 & & & \\
\end{tabular}

\footnotetext{
* Based on quantitative information; otherwise, the estimates are based on a combination of quantitative and qualitative evidence.
}

Source: see text

The conversion of the price and consumption of fuels into their equivalents in light requires estimates of the conversion of energy into light emission by different lighting technologies, be they candles, gas or oil lamps, or light bulbs. The rate of light emission from a source is the light flux/flow, which can be measured in lumens. A wax candle emits about 13 lumens, a sixty-watt incandescent filament bulb about 700 lumens and a fifteen-watt compact fluorescent bulb about 800 lumens (Nordhaus 1996). With these estimates, others in Nordhaus (1996), and the use of a simple diffusion model of generations of lighting technology, time series of the average lighting efficiency (in lumen-hours per $\mathrm{kWh}$ ) for tallow candles, gas lamps, kerosene lamps and electric lights were assembled. The implicit price or consumption of lighting (measured in lumen-hours ${ }^{6}$ ) using any particular technology can be calculated by multiplying the associated energy price or use by the efficiency. Building on these data, it was possible to estimate relatively reliable average lighting prices (by taking expenditure-weights for individual source-technology mixes) and lighting consumption (by summing individual sourcetechnology mixes) for England and then, roughly from the mid-nineteenth century, Britain and the United Kingdom.

\footnotetext{
${ }^{6}$ One million lumen-hours is roughly equivalent to having a 100-watt incandescent bulb lit for 100 hours.
} 


\section{Trends in Lighting and Energy for Lighting Consumption}

Before the mid-eighteenth century, at night, most people lived in near-complete darkness and only ventured out in the presence of moonlight. At the beginning of the nineteenth century, the main fuel for lighting, tallow, cost around $£(2000) 5,000$ per tonne of oil equivalent (see Figure 1) - as a comparison the average cost of heating fuels at the time was $£(2000) 120$ per tonne of oil equivalent (Fouquet 2011). Since then, the provision of artificial light has been revolutionised by a series of innovations in lighting technologies and appliances, fuels, infrastructures and institutions, allowing both the price of energy for lighting to fall and the efficiency of the lighting technology to improve dramatically.

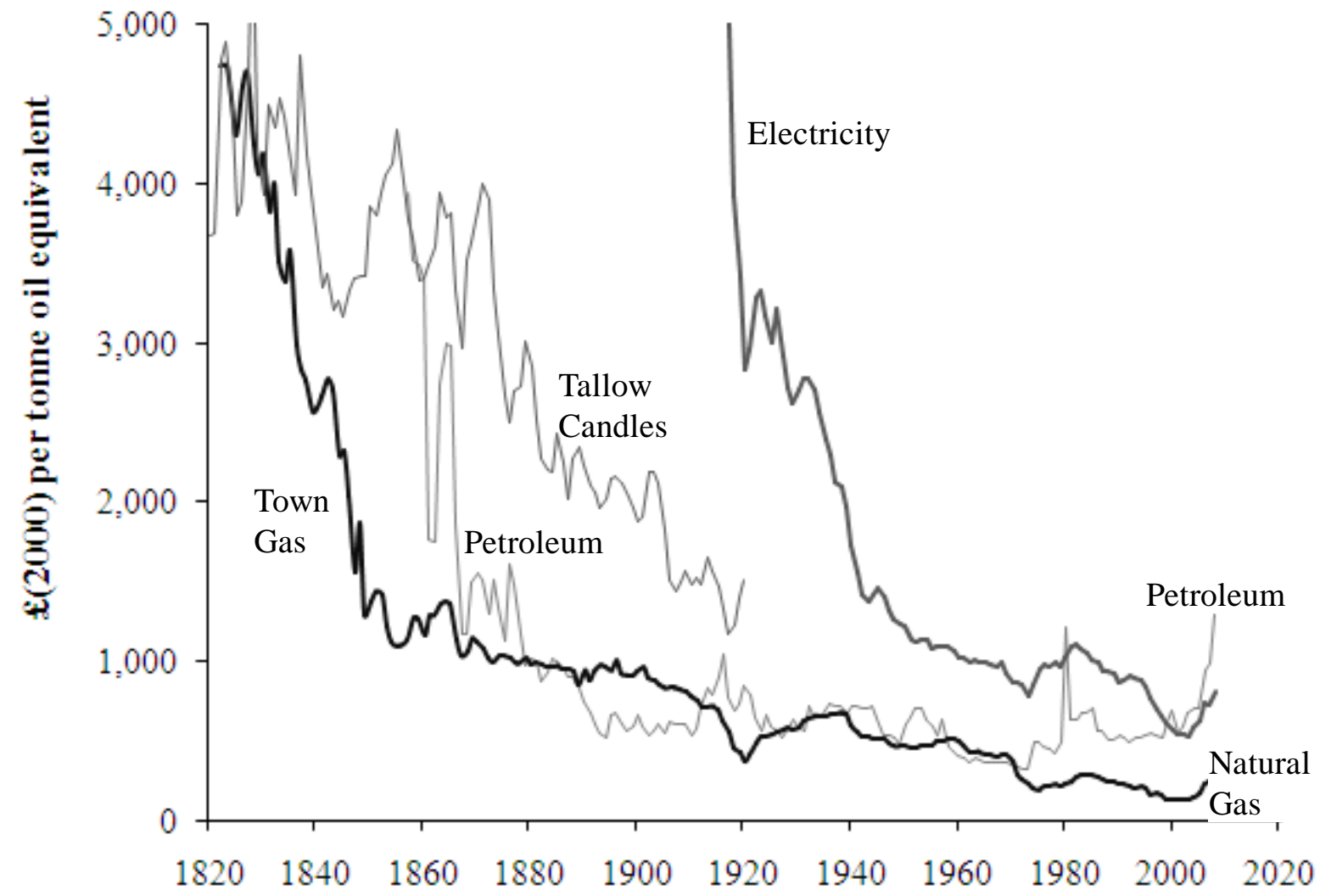

Source: Fouquet (2011)

Figure 1. Trends in the Prices of Energy Sources for Lighting, 1820-2008

The introduction of town gas (produced from coal) in the early 1800s allowed for cheaper lighting, because gas lamps (per unit of energy used for each lumen-hour of light generated) were twice as efficient as tallow candles. During the nineteenth century, the price of town gas fell dramatically (see Figure 1) and the efficiency of gas lamps improved much more dramatically, reducing the price of 
lighting more than thirty-fold between 1800 and 1900 (see Figure 2, noting the different scales on the vertical axes).

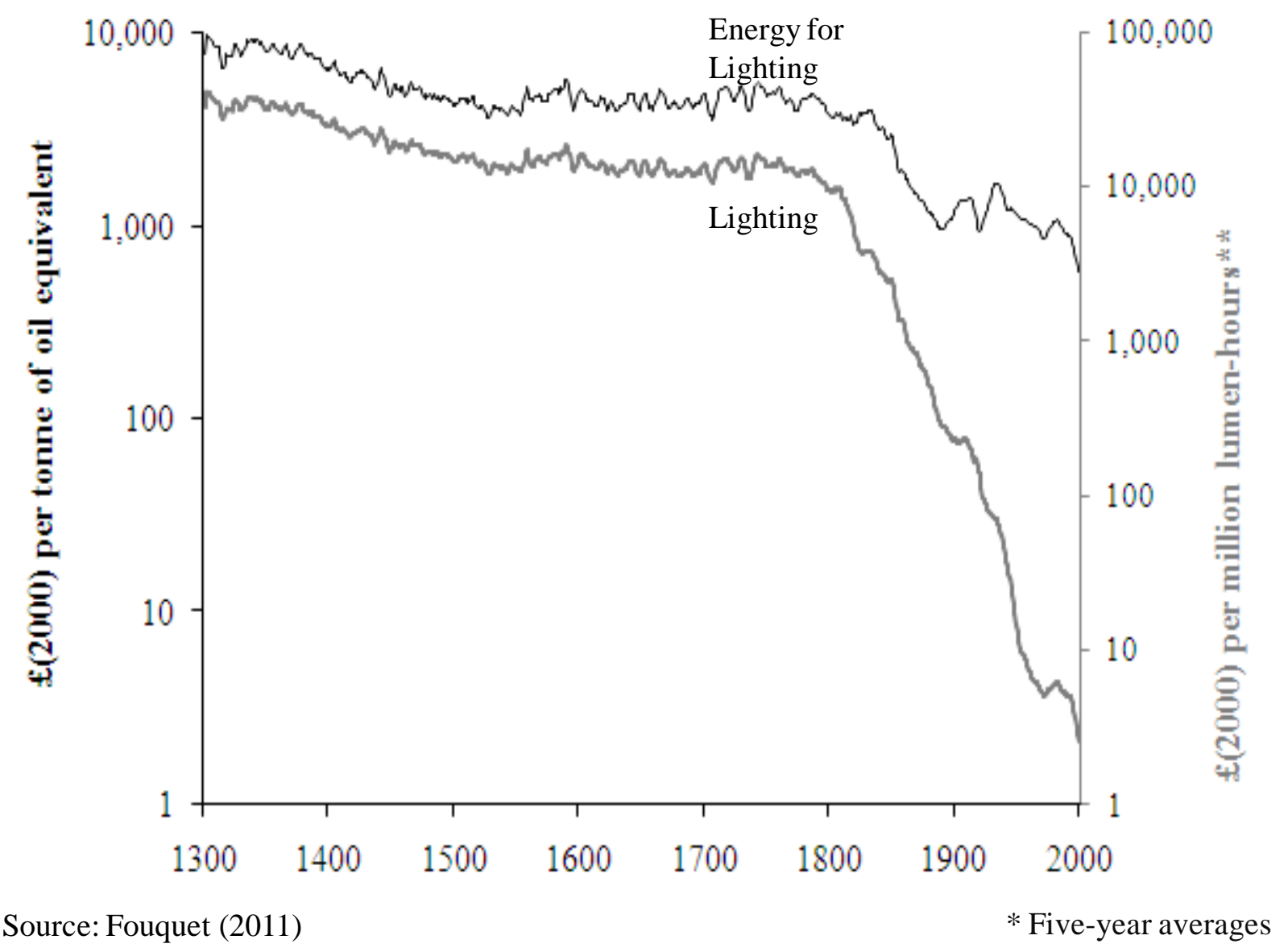

Figure 2. Trends in the Prices of Energy for Lighting and of Lighting Services*, 1300-2000

The transition from tallow candles to the dominance of town gas was rapid, taking from the 1810 s to until about 1850 (Fouquet 2010). This was partly the result of a rapidly expanding network of gas supply - in 1823, all twelve towns with more than 50,000 inhabitants had a gas supplier and, three years later, all towns over 10,000 had a company; by 1829 , there were 200 gas suppliers in the United Kingdom (Goodall 1999). In addition to cheaper lighting, gas offered a different lighting experience and reduced the risk of fires (Schivelbusch 1988) and the cost of insurance. Driven by cheaper and more desirable lighting and rising incomes (see Figure 3), total consumption of lighting increased 500-fold during the nineteenth century (see Figure 4). 


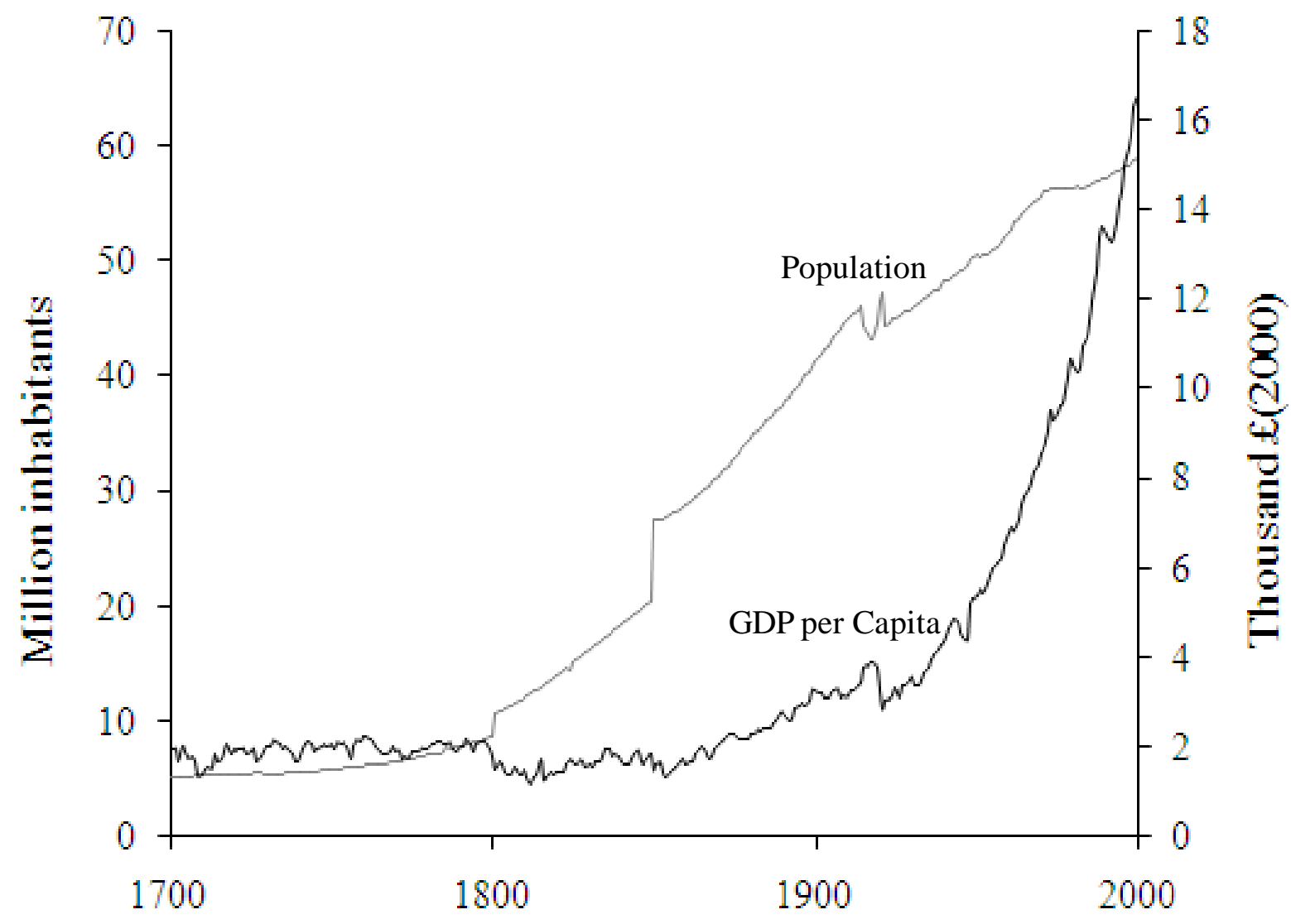

Source: ONS (2009), Mitchell (1988), Broadberry et al. (2009)

Figure 3. GDP per Capita and Population, 1700-2000

However, the high costs of installing pipes prohibited many households from accessing and using gas until the 1890s (when pre-paid coin in the slot meters were introduced). For poorer households, from the mid-nineteenth century, paraffin or kerosene (made from petroleum) became available, required much less expenditure on lamps and offered increasingly widespread fuel access as well as portability. So, from the 1860s, poorer populations were able to consume substantially more lighting. Kerosenelighting was cheaper than candle-lighting from its introduction (see Figure 1); and by the 1890s, it was starting to compete with gas lighting. Yet, kerosene, even at its peak in the early twentieth century (fifty years later), was never more than one-fifth of the total market for lighting. 


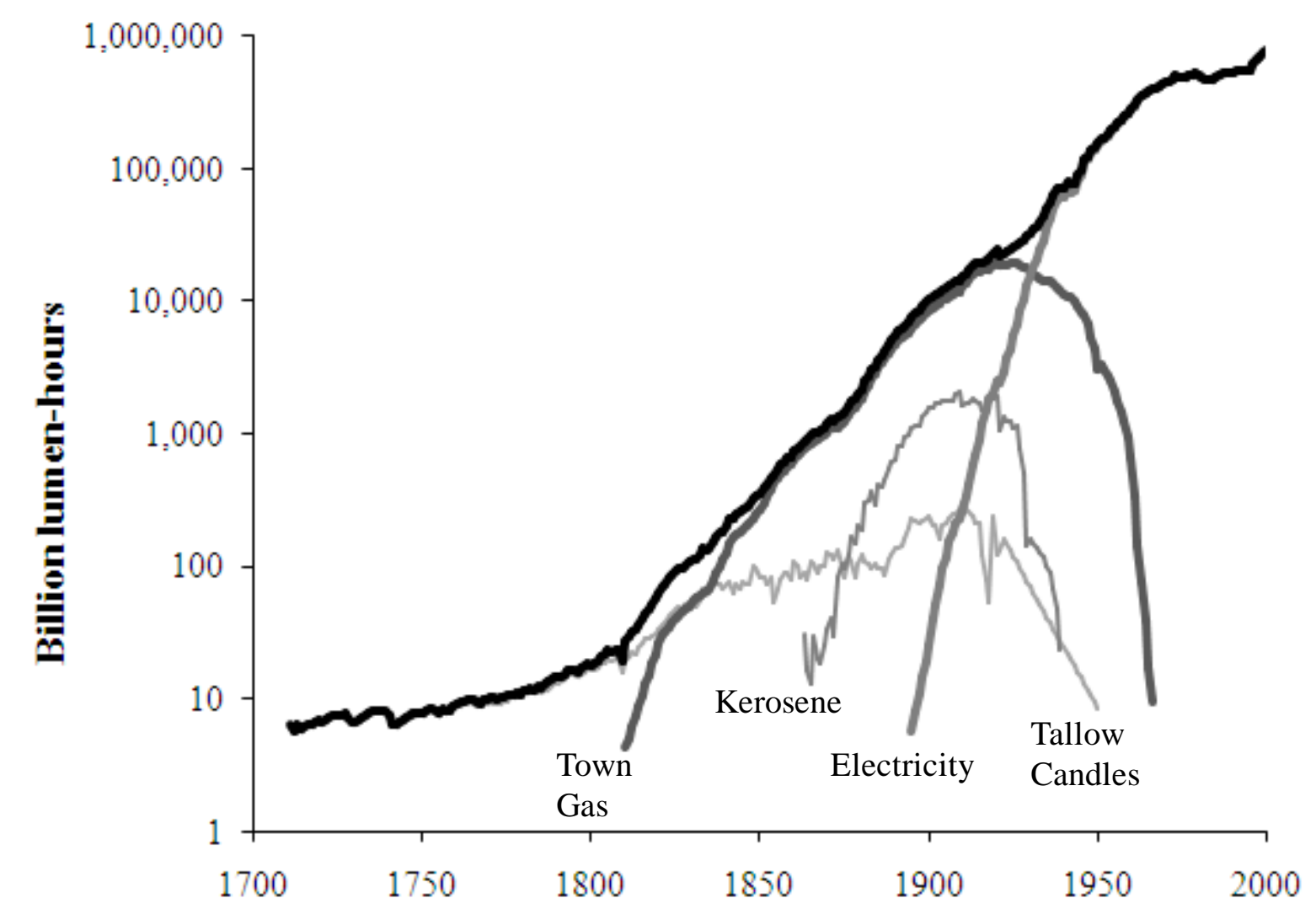

Source: Fouquet and Pearson (2006)

Figure 4. Consumption of Lighting by Source, 1700-2000

From the 1880s, with the introduction of Edison's and Swan's incandescent lamps, electricity began to compete with gas and kerosene in the market for lighting. The transition was gradual, however. The gas and gas lighting industries reacted to the threat and their technology improved dramatically once durable versions of the incandescent mantle, originally developed by Welsbach, were widely marketed and adopted. With the introduction of tungsten incandescent bulbs in 1915, and continuing reductions in the price of electricity (see Figure 1), electric lighting became cheaper than gas lighting in the 1920s, more than 40 years after the introduction of the incandescent bulb. Around this time, electricity began to dominate the market and overall lighting consumption grew further.

The incandescent light bulb and lighting efficiency changed little after the 1930s. It was only in the 1990s that lighting efficiency improved dramatically with the growth in the use of the compact fluorescent lights (CFLs). Although they are five-times more efficient than incandescent bulbs, their influence on average lighting prices has only begun to feed through, because consumers have not adopted the new technology as quickly as was expected (Frondel and Lohmann 2011). Nevertheless, 
lighting consumption has started increasing again, after a relatively flat last quarter of the twentieth century.

To summarize (see Table 2), the price of lighting services fell from $£(2000) 8,000$ per million lumenhours in 1800 , to $£(2000) 250$ in 1900 and to $£(2000) 2.5$ in 2000 - more than 3,000-fold in 200 years. Real income per capita increased from $£(2000) 1,750$ per year in 1800 to $£(2000) 3,200$ in 1900 and to $£(2000) 17,000$ in 2000 - nearly a ten-fold rise in 200 years. Total lighting consumption soared from less than 20 billion lumen-hours in 1800 to 10,000 billion lumen-hours in 1900 to nearly 800,000 billion lumen-hours in 2000 - a 40,000-fold rise in 200 years.

Per capita consumption (last column of Table 2) increased from 1,100 lumen-hours of artificial lighting in 1800 to 255,000 lumen-hour - a 220-fold increase. If lighting demand had been unit elastic in relation to both income and price during the nineteenth century, consumption would have increased less than 60-fold. In other words, demand for lighting in the nineteenth century was very elastic. Conversely, assuming unit elasticity in relation to income and price during the twentieth century would have led to a 500-fold increase in per capita consumption - instead, it increased a more modest 50-fold - to 13 million lumen-hours (i.e., in 2000, every day, the average British consumer used the equivalent of a 100-watt incandescent bulb lit for four hours). Thus, the evidence already puts inquestion a constant elasticity over the last two hundred years and suggests dramatic differences in income and/or price elasticity between the nineteenth and twentieth centuries.

Table 2. Price of Lighting, Per Capita Income, Total and Per Capita Lighting Consumption

\begin{tabular}{|c|c|c|c|c|}
\hline Year & $\begin{array}{l}\text { Price of lighting } \\
\text { services per million } \\
\text { lumen-hours } \\
\text { (£year 2000) }\end{array}$ & $\begin{array}{l}\text { Per capita } \\
\text { income } \\
\text { (£year 2000) }\end{array}$ & $\begin{array}{l}\text { Total lighting } \\
\text { consumption } \\
\text { (billion lumen- } \\
\text { hours) }\end{array}$ & $\begin{array}{l}\text { Per capita } \\
\text { lighting } \\
\text { consumption } \\
\text { (thousand } \\
\text { lumen-hours) }\end{array}$ \\
\hline 1800 & 8,000 & 1,750 & 18 & 1.1 \\
\hline 1850 & 2,600 & 1,500 & 355 & 13 \\
\hline 1900 & 250 & 3,200 & 10,500 & 255 \\
\hline 1950 & 18 & 5,400 & 155,000 & 3,100 \\
\hline 2000 & 2.5 & 17,000 & 775,000 & 13,000 \\
\hline
\end{tabular}

Sources: see text 


\section{Income and Price Elasticities, and Rebound Effects}

Econometric analysis of the data was necessary to identify the influence of income and prices on lighting consumption and to investigate how income and price elasticities changed through time and at different phases of economic development. For this policy journal the discussion focuses on the results rather than the methods and data. While we acknowledge that not everyone will agree with our approach to estimation, we think that it offers a useful first step. ${ }^{7}$

Given the trended nature of the data (see Figures 2 and 3) and the tendency for long run energy consumption, GDP and energy prices to be cointegrated (Hunt and Manning 1989, Fouquet 1997, Stern 2000, Mahadevan and Asafu-Adjaye 2007), the possibility of using vector error-correcting models (VECM) was explored. From a statistical perspective, such models were appropriate.

First, for the long run trends in lighting consumption per capita, GDP per capita and the price of lighting $^{8}$, non-stationarity ${ }^{9}$ could not be rejected. In addition to the standard tests for unit roots, an augmented Dickey-Fuller test where the time series is transformed via a generalized least squares (GLS) regression was used to improve the power of the test (Elliott, Rothenberg and Stock 1996). Here, for up to 15 lags, and incorporating the assumption of a time trend, the tau-statistics could not reject at the $10 \%$ confidence level. Thus, unit roots (i.e. non-stationarity) were likely.

Second, the causal relationship between per capita lighting consumption and per capita GDP was examined and the results suggest unidirectional causality from per capita GDP to per capita lighting

\footnotetext{
${ }^{7}$ Lutz Killian questioned whether long run elasticities can be estimated with time series, rather than with panel data (See Killian and Murphy 2009). Bill Nordhaus, David Stern and Lester Hunt encouraged us to pursue this line of research, although offered caution about the methods. (see, for instance, Hunt et al. 2003). Naturally, the authors of this paper are solely responsible for the choices made and the limitations of the methods used.

${ }^{8}$ Other variables might have been included. Urbanisation and energy supply infrastructure could have been interesting to include, although they are likely to have been highly correlated with GDP per capita, making it difficult to identify the influence of specific (correlated) variables on lighting consumption. The average price of lighting equipment might also have influenced consumption. Unfortunately, the authors have failed to find sufficient data on the prices of lamps, for instance, to use in this long-run analysis. Finally, following David Stern's advice, the price of lighting was kept as a single variable rather than separated into the price of energy and lighting efficiency, since consumers are assumed to respond to both variables in the same way - as changing the price of lighting.

${ }^{9}$ Non-stationary series do not tend to revert to an average value. Similarly, although they appear to increase or decrease through time, these series do not revert to an average trend, Instead, they tend to drift through time, as a result of shocks with a long-run effect. Econometric analyses of these non-stationary series risk generating spurious correlations and results - because, for certain periods, these series may appear to increase or decrease jointly with other unrelated series, Thus, it is important to identify whether they are co-integrated with other series (that is, the series do actually drift together) or their apparently joint drifts are merely a statistical coincidence (Bannerjee et al. 1993, Rao 1994).
} 
consumption ${ }^{10}$. No variable individually had an influence on GDP per capita or on the price of lighting. This is expected for GDP, as lighting has been only a small component of economic activity. Similarly, the dramatic changes in energy markets and in lighting technology were not necessarily driven by increases in income or lighting consumption.

Third, tests rejected the null hypothesis of no cointegrating equations for the relationship between lighting consumption, GDP per capita and the price of lighting - for most of the period between 1711 and 2008 (see below). Having selected the appropriate number of lags from a series of different tests (Nielson 2001), tests for the existence of cointegrating equations were performed and, when the null hypothesis of no relationship was rejected, almost always one cointegrated relationship could not be rejected (based on methods developed in Johansen 1988, 1995).

These VECM were, therefore, used to estimate the evolution of income and price elasticities. The approach was to estimate elasticities for fifty year periods ${ }^{11}$ moving through time. For example, the income and price elasticities were estimated for the period 1715-1765, then 1716-1766, and so on until 1958-2008. Then, the elasticity for any particular year would be the moving average (i.e., the average of all elasticities estimated where that year was included). For example, for the moving average around the year 1950, fifty income elasticity estimates were produced (for the periods 19001950, 1901-1951, and so on until 1950-2000) and the average of all these estimates was equal to 1.01. Estimated in the same way, the average price elasticity around $1950^{12}$ was -0.47 .

Inevitably, for some periods, the results were either not as expected or the possibility of no cointegrated relationship could not be rejected with $95 \%$ confidence. In particular, the period broadly between 1850 and 1870 produced unexpected income elasticities and the absence of cointegrating relationships could not be rejected. The income elasticities were negative and large (i.e. generally -2 and -10). In the absence of a satisfactory explanation, these estimates were excluded from the calculation of the average estimates - thus for years (1853-1864) that have less than five estimates, no average was calculated. Nevertheless, over nearly three hundred years, the majority of estimates

\footnotetext{
${ }^{10}$ As David Stern reminded the authors, while for lighting, the relationship between consumption and GDP appears uni-directional, for other (more important) energy services, consumption may also influence GDP (see also Stern 2000).

${ }^{11}$ The choice of fifty year periods reflected the need for sufficiently long periods to generate statistically significant results and capture the possibility of cointegrated relationships, but also for periods to be short enough to identify behavioural changes, reflected by varying elasticities, through time.

${ }^{12}$ In one sense, it is an average from 1900-2000, but the average is made up of 50 elasticity estimates 1900$1950,1901-1951, \ldots, 1950-2000$, where the year 1950 is in all 50 estimates, and 1900 and 2000 are each in only 1 of the estimates. Thus, in the results, when an estimate for a particular year (say, 1950) is presented, it is the moving average around 1950, where the year 1950 is given maximum weighting, while, for instance, 1900 and 2000 are only given $2 \%$ weighting.
} 
produced standard signs and sizes - income elasticity estimates were used for $88 \%$ of the moving averages and price elasticity estimates for $99.5 \%$ of the moving averages.

Figure 4 presents the trends in the moving average estimates (the numbers are shown in Table 3 ). The most striking feature is the dramatic increase in income elasticity between the 1840s and the 1890s. Before the 1840s, households tended to use $7 \%$ more lighting when their income rose by $10 \%$. The results suggest that, in the 1890s, the responsiveness was five times greater - a $10 \%$ increase in income led to a $35 \%$ increase in lighting consumption. At the same time, price elasticity also increased from the 1840 s, peaking in the 1860 s, when a $10 \%$ decrease in lighting prices (due to cheaper gas or kerosene and perhaps also improvements in lamp efficiency) appears to have generated $17 \%$ more lighting consumption.

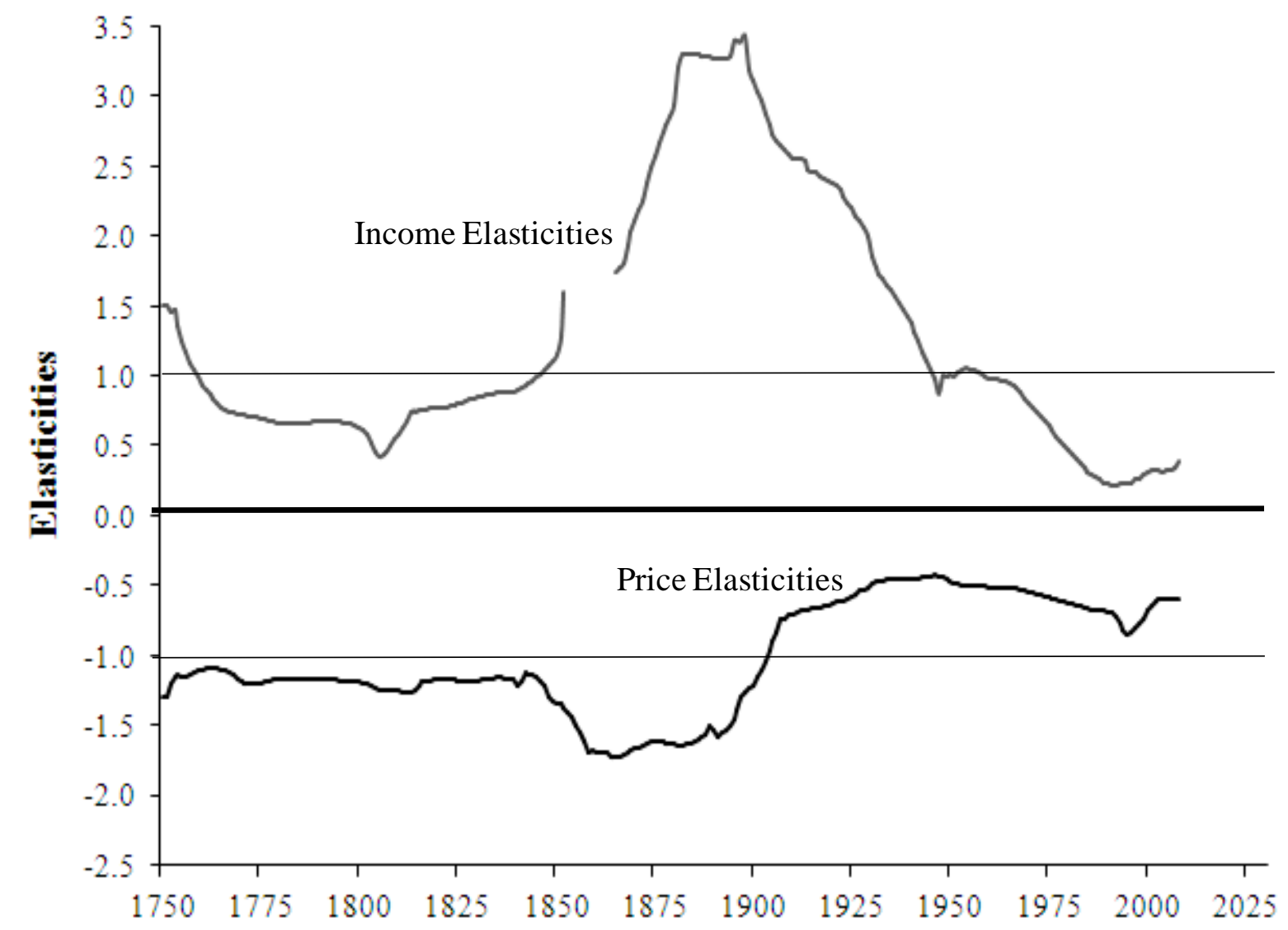

Source: See Text

Figure 4. Income and Price Elasticities at Different Phases of Economic Development 
Table 3. Decadal Averages of Income and Price Elasticities of Demand for Lighting, 1750-2010

\begin{tabular}{ccccccccc}
\hline Decade & $\begin{array}{c}\text { Income } \\
\text { Elasticity }\end{array}$ & $\begin{array}{c}\text { Price } \\
\text { Elasticity }\end{array}$ & Decade & $\begin{array}{c}\text { Income } \\
\text { Elasticity }\end{array}$ & $\begin{array}{c}\text { Price } \\
\text { Elasticity }\end{array}$ & $\begin{array}{c}\text { Income } \\
\text { Decade }\end{array}$ & $\begin{array}{c}\text { Price } \\
\text { Elasticity }\end{array}$ & Elasticity \\
\hline 1750 & 1.3 & -1.2 & 1840 & 1.0 & -1.2 & 1930 & 1.6 & -0.5 \\
1760 & 0.8 & -1.1 & 1850 & 1.4 & -1.5 & 1940 & 1.1 & -0.4 \\
1770 & 0.7 & -1.2 & 1860 & 1.9 & -1.7 & 1950 & 1.0 & -0.5 \\
1780 & 0.7 & -1.2 & 1870 & 2.5 & -1.6 & 1960 & 0.9 & -0.5 \\
1790 & 0.7 & -1.2 & 1880 & 3.3 & -1.6 & 1970 & 0.7 & -0.6 \\
1800 & 0.5 & -1.2 & 1890 & 3.3 & -1.4 & 1980 & 0.3 & -0.7 \\
1810 & 0.7 & -1.2 & 1900 & 2.8 & -0.9 & 1990 & 0.2 & -0.8 \\
1820 & 0.8 & -1.2 & 1910 & 2.5 & -0.7 & 2000 & 0.3 & -0.6 \\
1830 & 0.9 & -1.2 & 1920 & 2.2 & -0.6 & & & \\
\hline
\end{tabular}

It seems that the expansion of access to and use of gas lighting for the upper and growing middle classes who could afford it (from the 1840s) and the introduction of kerosene (in the 1860s), which was helpful for poorer households, led to a spectacular increase in demand. As well as the chance to satisfy a latent demand for better illumination, it may also reflect a dramatic change in people's perception of the potential and value of lighting and of opportunities to re-frame their lifestyles.

It is possible that below certain levels of access, quality and affordability, lighting provides only a little relief from the darkness. However, beyond a threshold, lighting becomes an "enabler" or complement of other goods and services. In particular, when sufficient illumination becomes available, many more activities become possible at night, including working, socialising and education, as well as assisting in the development of urbanisation and reducing related crime. Thus, as well as rising incomes and falling prices, the opportunities that access to better lighting offered may perhaps explain why late Victorian Britain had such a voracious appetite for light.

Indeed, for the period 1850 to 1950 , income elasticity appears to have been greater than one. An interpretation of the trends in income elasticity is that, before 1850 basic lighting was needed simply to enable people to complete chores in the house, but that access to this level of basic lighting did improve with income. From the mid-nineteenth century, additional activities became highly desirable with higher income and better lighting appliances, and lighting became a 'luxury' good (peaking around 1900). The intensity of desire started to decline, as these additional activities became part of everyday life, and lighting services became 'necessities' around 1950. 
Similarly, according to these estimates, price elasticities were greater than one from 1750 until around 1900. That is, reductions in energy prices led to proportionally larger increases in per capita energy consumption. Similarly, all other things being constant, efficiency improvements in lighting technology resulted in backfire (i.e., increases in per capita energy consumption).

If we decompose price elasticity into its two components, the income effect appears to have increased in the second-half of the nineteenth century. Before then, about $1 \%$ of an average income was spent on lighting. This doubled by around 1850 (Fouquet 2008 p.271). This implies that declining lighting prices in 1850 would have had twice as much effect on consumer purchasing power than in 1800 . Nevertheless, even though the cost of illuminating a house fell remarkably in the nineteenth century, lighting was always a small share of the household's total budget, implying that the income effect would have been small. Thus, the substitution effect seems likely to have been a stronger factor determining the change in the price elasticity. The rapidly declining price of lighting (30-fold from 1800 to 1900) made it dramatically cheaper compared to other expenditures in the household - for example, in relation to other energy services: heating costs fell by $40 \%$ and the costs of passenger transport dropped three-fold during the nineteenth century (Fouquet 2008 p.255).

These large elasticities are not surprising given the striking increases in lighting consumption during the eighteenth and nineteenth centuries. Yet, it is valuable to separate-out the influence of income and of prices. Indeed, it appears that, during the first half of the twentieth century, consumers were still likely to more than proportionately increase lighting use as their incomes rose. However, responsiveness to income fell dramatically around the time of the Oil Shocks of the 1970s, and demand now appears to increase only relatively little with income.

Especially during the twentieth century, falling prices led to less than proportionate increases in lighting demand and consumption. That is, efficiency improvements did appear to lead to net energy savings, all other things being constant. Yet, it also clear that, even in the twentieth century and at the beginning of the twenty-first century, a $10 \%$ energy efficiency improvement in lighting led to less than $5 \%$ reduction in per capita energy consumed for lighting. That is, rebound effects in the lighting market were still strong, although they do not suggest backfire.

\section{Conclusion}

This paper sought to estimate the real income and price elasticities of demand for lighting, and to explore whether and how they have changed over different phases of economic development. Focussing on the experience in what became the United Kingdom, it tried to separate-out the influence of the impressive decline in the real price of lighting (3,000-fold between 1800 and 2000) 
and the effect of the increase in per capita income (10-fold between 1800 and 2000) on the spectacular leap in total lighting consumption (40,000-fold over the two centuries) and in per capita lighting consumption (13,000-fold over this period). Using standard econometric techniques and modelling of long run economic behaviour, we estimated a series of income and price elasticities. For each year, a moving average estimate was calculated, thus providing a time series of the income and price elasticities from the middle of the eighteenth century to the beginning of the twenty-first century.

The results suggested significant changes in both income and price elasticities of lighting service demand over the period. Until the mid-nineteenth century, income elasticities were about 0.7 and price elasticities about 1.2. This latter value suggests that during this period, the rebound effect was large enough to imply backfire: energy efficiency improvements led to increases in energy used for lighting. Then, between the 1840 s and the 1890 s income and price elasticities increased dramatically. A $10 \%$ price decrease or $10 \%$ efficiency improvement led to $17 \%$ more lighting consumption, substantially increasing energy consumption. Even more impressively, a $10 \%$ increase in per capita income appeared to generate 35\% more lighting use and, all other things being constant, energy requirements. Between 1900 and 1950, income elasticity fell to unity, before dropping to between 0.25 and 0.4 at the beginning of the twenty-first century. Throughout the twentieth century, price elasticity and the rebound effect have ranged between 0.5 and 0.7 , showing considerable stability.

It is appropriate to reiterate earlier caveats about the reliability and coverage of the data and the validity of the econometric procedures. This is easy to do, particularly for the early period data. And it may be that the elasticities are artefacts of the estimation methods. However, the econometric estimates broadly match the data - that is, between 1800 and 1900, jointly income and price elasticities are greater than one and, between 1900 and 2000, they are less than one - and our expectations - that is, elasticities are high at low levels of economic development and fall as the economy reaches higher levels of per capita income. It is also in-line with studies focussing on energy consumption (see, for instance, Mahadevan and Asafu-Adjaye 2007).

The long run trends and the relative stability of the price elasticity estimates suggest that the EU ban on inefficient incandescent light bulbs could lead to a modest reduction in energy consumption for lighting in the United Kingdom. In time, these savings seem likely to be eroded by rising income levels, albeit with a relatively low income elasticity, and perhaps also by new uses for solid state lighting. Of course, the implications for carbon emissions depend on both the level of electricity demand and the carbon intensity of future electricity supplies.

The implications for developing economies of the new generation of improvements in energy efficient lighting are more important than the prospects for the United Kingdom. Some have proposed that rebound effects in developing economies are likely to be greater than in today's industrialised economies (Schipper 2000, Roy 2000). This study suggests that this was the pattern in the United 
Kingdom, in that income and price elasticities rose substantially as incomes rose and lighting prices fell. If this kind of growth pattern were to be replicated in developing countries, then the combination of rising incomes and access to much more efficient lighting technologies could imply that the consumption of lighting would grow very rapidly. This could be accelerated in those countries in which the major rise in income and the dramatic fall in lighting prices get compressed into a few decades, rather than the two centuries required in the United Kingdom. And, of course, in addition to rebound effects from enhanced efficiency, lighting use will be fed inter alia by urbanisation, industrialisation, electrification, population growth and aspirations to emulate desired lifestyles.

Returning to the role efficiency improvements might play in consumption behaviour, in the United Kingdom backfire appears to have occurred between 1750 and 1900 at levels of income below about $£(2000) 3,300$ per capita income (or roughly \$(2010)6,000); at higher income levels efficiency improvements were associated with energy savings. It is not certain, however, that future efficiency improvements would necessarily generate backfire in economies with income levels of $\$(2010) 6,000$; this is partly because many efficiency improvements, including incandescent bulbs, have already been factored-in to the price of lighting in significant parts of some developing economies. Thus even if such economies have experienced backfire in the past, the future may not generate such high rebound effects.

This exploratory study of elasticities of demand for lighting services suggests that it would be worth investigating the evolution of the demand for other energy services at different phases of economic development. The process of industrialisation involves vast quantities of heating, of power and of freight transportation (Fouquet 2008). Similarly, the process of increasing disposable income tends to lead to demands for greater mobility and passenger transportation. So, a study of related elasticities might reveal interesting insights into the drivers of past energy requirements in industrialised economies and better understanding of prospective energy demands and associated carbon dioxide emissions in developing economies. And, given the probable high income elasticities, it is doubtful how much the internalisation of external costs would slow the growth in the consumption of energy services or of energy in developing countries, with major implications for both the quality of life and for carbon emissions. 


\section{References}

Administrative Council of London. (1920). Electricity Supply 1917-1920. London County Council. London.

Allen, R.C. (2007). Pessimism Preserved: Real Wages in the British Industrial Revolution. Economics Series Working Papers 314. University of Oxford. Department of Economics.

http://www.nuffield.ox.ac.uk/General/Members/allen.aspx

Banerjee, A. Dolado, J. Galbraith, J.W., and Hendry, D. (1993). Co-integration, Error Correction, and the Econometric Analysis of Non-Stationary Data. Oxford University Press. Oxford.

Beveridge, W. (1894). Prices and Wages in England: From the Twelfth to the Nineteenth Century. London: Longmans, Green and Co.

BP. (2011). BP Statistical Review of World Energy. London: BP.

BPP - British Parliamentary Papers (1896) Reports of the Select Committee Report on Petroleum. Irish University Press. Shannon, Ireland.

Broadberry, S. Campbell, B., Klein, A., Overton, M. and van Leeuwen, B. (2009). British Economic Growth, 1270-1870, Working Paper.

http://www2.lse.ac.uk/economicHistory/pdf/Broadberry/BritishGDPLongRun.pdf

DTI - Department of Trade and Industry (2001 and backdates) Digest of United Kingdom Energy Statistics. London: HMSO.

Elliott, G., Rothenberg, T.J. and Stock, J.H. (1996). Efficient tests for an autoregressive unit root. Econometrica 64 813-36.

Fouquet, R. (2008). Heat Power and Light: Revolutions in Energy Services. Cheltenham and Northampton, MA, USA: Edward Elgar Publications.

Fouquet, R. (2010). 'The Slow Search for Solutions: Lessons from Historical Energy Transitions by Sector and Service'. Energy Policy. 38(10) 6586-96.

Fouquet, R. (2011). 'Divergences in long run trends in the prices of energy and energy services.' Review of Environmental Economics and Policy 5(2).

Fouquet, R. and P.J.G. Pearson. (2006). 'Long Run Trends in Energy Services: The Price and Use of Lighting in the United Kingdom, 1300-2000.’ The Energy Journal. 25(1): 139-77.

Fouquet, R., D. Hawdon, P.J.G. Pearson, C. Robinson and P.G. Stevens. (1997). 'The future of UK final user energy demand.' Energy Policy 25(2) 231-40.

Frondel, M., Lohmann, S. (2011). The European Commission's Light Bulb Decree: Another Costly Regulation? Ruhr Economic Papers no.245. Ruhr University Bochum.

Frondel, M., Peters, J., Vance, C. (2008). 'Identifying the Rebound: Evidence from a German Household Panel.' The Energy Journal 29 (4), 154-163. 
Goldemberg, J., T.B. Johansson, A.K.N. Reddy and R.H. Williams. (1985). 'An End Use Oriented Energy Strategy.' Annual Review of Energy and the Environment. 10: 613-688.

Goodall, F. (1999). Burning to Serve: Selling Gas in Competitive Markets. Landmark Publishing. Ashbourne.

Greening, L. A., Greene, D. L., Difiglio, C. (2000). 'Energy efficiency and consumption - the rebound effect - a survey.' Energy Policy 28 (6-7), 389-401.

Haas, R., N. Nakicenovic, A. Ajanovic. (2008). Towards sustainability of energy systems: A primer on how to apply the concept of energy services to identify necessary trends and policies. Energy Policy. 36(11): 4012-4021.

Howarth, R.B. (1997), 'Energy efficiency and economic growth.' Contemporary Economic Policy 15(4) 1-9.

Howarth, R.B., Haddad, B.M., Paton, B. (2000). 'The economics of energy efficiency: insights from voluntary participation programs.' Energy Policy 28(6/7) 477-486.

Hunt, L.C. and Manning, N. (1989). 'Energy price- and income-elasticities of demand: some estimates for the UK using the cointegration procedure.' Scottish Journal of Political Economy 36(2) 183-93.

Hunt, L.C., Judge, G., Ninomiya, Y. (2003). 'Underlying trends and seasonality in UK energy demand: a sectoral analysis.' Energy Economics 25(1) 93-118.

Jevons, W.S. (1865). The Coal Question: An Inquiry Concerning the Progress of the Nation, and the Probable Exhaustion of Our Coal-Mines. Macmillan. London.

Johansen, S. (1988). 'Statistical analysis of cointegration vectors.' Journal of Economic Dynamics and Control 12 231-54.

Johansen, S. (1995). Likelihood-Based Inference in Cointegrated Vector Autoregressive Models. Oxford University Press. Oxford.

Khazzoom, J.D., (1980). 'Economic implications of mandated efficiency in standards for household appliances.' Energy Journal, Vol. 1, No.4, pp. 21-40.

Kilian, L., Murphy, D, (2010). The Role of Inventories and Speculative Trading in the Global Market for Crude Oil, CEPR Discussion Papers 7753.

Mahadevan, R. and Asafu-Adjaye, J. (2007). 'Energy consumption, economic growth and prices: A reassessment using panel VECM for developed and developing countries.' Energy Policy 35 24812490

Mills, E. (2002). 'The \$230-billion global lighting energy bill.' Proceedings of the Fifth European Conference on Energy-Efficient Lighting, International Association for Energy-Efficient Lighting, Stockholm, pp. 368-385 <http://eetd.lbl.gov/ea/EMills/LightingPublications.html>

Mills, B. F. Schleich, J. (2010). 'Why don't households see the light?: Explaining the diffusion of compact fluorescent lamps.' Resource and Energy Economics 32(3) 363-378.

Mitchell, B.R. (1988). British Historical Statistics. Cambridge: Cambridge University Press. 
MOFP - Ministry of Fuel and Power. (1951). Statistical Digest 1950. London: HMSO.

MOP - Ministry of Power. (1961). Statistical Digest 1960. London: HMSO.

Nielsen, B. (2001). Order Determination in General Vector Autoregressions. Working Paper. Department of Economics. University of Oxford and Nuffield College.

Nordhaus, W.D. (1996). 'Do real output and real wage measures capture reality? The history of lighting suggests not.' In The Economics of New Goods, ed. T.F. Breshnahan and R. Gordon. Chicago: Chicago University Press.

Rao, B.B. (1994). Cointegration for the Applied Economist. Macmillan. London.

Rogers J.E.T. (1865, 1882, 1886). A History of Agriculture and Prices in England. Vol I-VI. Oxford: Clarendon Press.

Roy, J. (2000). 'The rebound effect: some empirical evidence from India.' Energy Policy 28(6/7) 433438.

Saunders, H.D. (1992). 'The Khazzoom-Brookes postulate and neoclassical growth.' The Energy Journal, 13(4), pp. 131-145.

Schipper, L. (2000). 'On the rebound: the interaction of energy efficiency, energy use and economic activity. An introduction.' Energy Policy 28(6/7) 351-3.

Schivelbusch, W. (1988) Disenchanted Night: The Industrialization of Light in the Nineteenth Century. Berg. Oxford.

Sorrell,S., (2007). The Rebound Effect: An Assessment of the Evidence for Economy-Wide Energy Savings from Improved Energy Efficiency. UK Energy Research Centre, London.

Sorrell, S., and Dimitropoulos, J. (2007). 'The rebound effect: microeconomic definitions, limitations and extensions.' Ecological Economics, 65(3), pp.636-649.

Sovacool, B.K. (2011). 'Conceptualizing urban household energy use: Climbing the "Energy Services Ladder’', Energy Policy 39 1659-1668.

Stern, D.I. (2000). 'A multivariate cointegration analysis of the role of energy in the US macroeconomy.' Energy Economics 22(2) 267-83.

Tsao, J.Y., Saunders, H.D., Creighton, J.R., Coltrin, M.E. and Simmons, J.A.( 2010). 'Solid-state lighting: an energy-economics perspective.' Journal of Physics D: Applied Physics 43 (2010)

Tsao, J.Y. and Waide, P. (2010). 'The World's Appetite for Light: Empirical Data and Trends Spanning Three Centuries and Six Continents', LEUKOS 6(4) April 2010

van den Bergh, J.C.M. (2011). 'Energy conservation more effective with rebound policy.' Environmental and Resource Economics 48(1) 43-58.

Wei, T. (2010). 'A general equilibrium view of global rebound effects.' Energy Economics, 32: 661672. 


\title{
BC3 WORKING PAPER SERIES
}

\author{
Basque Centre for Climate Change (BC3), Bilbao, Spain
}

The BC3 Working Paper Series is available on the internet at the following addresses:

http://www.bc3research.org/lits_publications.html

$\underline{\text { http://ideas.repec.org/s/bcc/wpaper.html }}$

BC3 Working Papers available:

2010-09

Roger Fouquet: The Sustainability of 'Sustainable' Energy Use: Historical Evidence on the Relationship between Economic Growth and Renewable Energy

2010-10

Karen Pittel and Dirk Rübbelke: Energy Supply and the Sustainability of Endogenous Growth

2010-11

2010-12

Ramon Arigoni Ortiz, Alexander Golub, Oleg Lugovoy, Anil Markandya and James Wang: The DICER Model: Methodological Issues and Initial Results.

Elena Ojea, Julia Martin-Ortega and Aline Chiabai: Classifying Ecosystem Services for Economic Valuation: the Case of Forest Water Services

Aline Chiabai, Chiara Travisi, Anil Markandya, Helen Ding, and Paulo Nunes: Economic Assessment of Forest Ecosystem Services Losses: Cost of Policy Inaction

Kaysara Khatun: Competing Ecosystem services: an Assessment of Carbon and Timber in the Tropical forests of Central America

Karen Pittel and Dirk Rübbelke: Local and Global Externalities, Environmental Policies and Growth

Margherita Grasso, Matteo Manera, Aline Chiabai, and Anil Markandya: The Health Effects of Climate Change: A Survey of Recent Quantitative Research

Luis Mari Abadie, Ramon Arigoni Ortiz and Ibon Galarraga: The Determinants of Energy Efficiency Investments in the U.S.

Roger Fouquet: Long Run Trends in Energy-Related External Costs

2011-02

2011-03

Dirk Rübbelke: International Support of Climate Change Policies in Developing Countries: Strategic, Moral and Fairness Aspects

2011-04

Melanie Heugues: Endogenous Timing in Pollution Control: Stackelberg versus Cournot-Nash Equilibria

2011-05

Karen Pittel and Dirk Rübbelke: International Climate Finance and its Influence on Fairness and Policy

Wan-Jung Chou, Andrea Bigano, Alistair Hunt, Stephane La Branche, Anil Markandya, Roberta Pierfederici: Households' WTP for the Reliability of Gas Supply

2011-06

Roger Fouquet and Peter J.G. Pearson: The Long Run Demand for Lighting: Elasticities and Rebound Effects in Different Phases of Economic Development 